\title{
Requirements Determination as a Social Practice: Perceptions and Preferences of Novice Analysts
}

\author{
Issam Jebreen ${ }^{1}$ \\ ${ }^{1}$ Faculty of Information Technology, Applied Science University, Jordan \\ Correspondence: Issam Jebreen, Faculty of Information Technology, Applied Science University, Amman, \\ Jordan. E-mail: issamjebreen@gmail.com
}

Received: March 11, 2015

Accepted: June 15, 2015

Online Published: July 25, 2015

doi:10.5539/cis.v8n3p134

URL: http://dx.doi.org/10.5539/cis.v8n3p134

The research is financed by Applied Science Private University, Amman, Jordan,

\begin{abstract}
At its core, Requirements Determination (RD) is fundamentally a collaborative social practice that involves multiple stakeholders who must work together to communicate, discuss and finally confirm the requirements for the system to be implemented or updated. With a potentially large number of (groups of) stakeholders involved, each with their own perspective on the system as well as their own level of understanding, the form and nature of communication in the $\mathrm{RD}$ process are worth investigating and improving, particularly given the impact of $\mathrm{RD}$ on other stages of software development, operation, and support. The many human interfaces associated with RD can lead to a variety of communication challenges, including miscommunication between users and analysts and misunderstandings between analysts and developers, all of which can add time and cost to software projects. In this paper we report on our use of the Communicative Adaptability Scale (CAS) questionnaire to assess the communicative competence of 45 novice analysts in social interaction. Through the questionnaire we have investigated the perceptions of analysts regarding the most effective channels through which to receive and send relevant RD information. Analysis leads us to confirm that first, face-to-face communication is the channel that our novice analysts prefer to employ in order to communicate with users during RD. Second, our novice analysts consider themselves to have the ability and desire to communicate in novel social contexts. The outcome of these experiences is the development and refinement of a social communication repertoire. Third, and less positively, our novice analysts consider themselves to have a lesser ability to engage in conversations with others who were not known previously. Furthermore, our analysis shows that our novice analysts perceive themselves to have limited competence to clearly express their ideas. Specifically, our analysts believe they have limited competence in word choice, pronunciation, and grammatical structure to express their ideas in a manner appropriate to the social context. Preferred channels of communication are confirmed, but their utility will be moderated by analysts' ability to interact in social settings. Additional training in communication skills, particularly articulation, may be of particular benefit to novice analysts.
\end{abstract}

Keywords: requirements determination, social practice, communication competence, novice analysts, communicative adaptability scale (CAS)

\section{Introduction}

Requirements determination (RD) has been defined as "a systematic approach to eliciting, organizing, and documenting the requirements of the system and a process that establishes and maintains agreement between the customer and the project team on the changing requirements of the system" (Siau, Tan, \& Sheng, 2010). This process inherently involves more than 'just' understanding the features and capabilities needed within the system that is to be designed for the users - it also involves the "identification of goals, assumptions, opinions, and desires of users" (Browne \& Ramesh, 2002). Many systems continue to be considered of low quality, due in part to poor communication between analysts and other stakeholders during the requirements determination process (Coughlan, Lycett, \& Macredie, 2003). Communication between stakeholders plays a central role in requirements determination. In particular, analysts and users must generally understand and agree among themselves upon the requirements of a system. Thus there may be miscommunication between users and analysts, and misunderstandings between analysts and developers, all of which can add time and cost to software projects. 
In recognition of these issues, the requirements analyst (RA) plays one of the key roles in ensuring project success.

Within the RD process analysts need to undertake a number of tasks that may demand particular skill sets. Several researchers have therefore approached the analysis of information systems development by focusing on the role of the RA and the need for specific skills. Walz and Wynekoop (1997) presented a ranking system based on the skills of employees involved in the software process. The three categories they found that analysts can fall into are: 1) those who are best with their technical skills; 2) those who are best at communicating with the users in order to identify the requirements and arrange them technically; and 3) those who are best at management.

Communication has therefore been acknowledged as one of the key varying factors influencing (mis)understanding during the RD phase. This paper contributes to the potential improvement of the RD process by exploring and investigating some of the key social challenges that can affect the efficacy of communication between novice analysts and user stakeholders.

In Section 2 we review literature related to our work. In Section 3 we briefly describe the research method. In Section 4 we present our findings and results, which are then discussed in Section 5. Finally, Section 6 sets out our conclusions and considers future work.

\section{Related Work}

Literature on the RD process has consistently stressed the significance of communication between stakeholders. For instance, Browne and Ramesh noted that "[p]roblems in communication lead to difficulties in the information gathering and verification stages of the requirements determination process" (Browne \& Ramesh, 2002). Havelka (2002) commented that communication with users was identified by IS specialists as being critical to the RD process. Gallivan and Keil (2003) noted that "[m]uch of the prior research on user participation assumes that user-developer communication will ensure that the resulting system will be designed to meet users' needs and will be accepted by them". Bostrom (1989) suggested that effective communication enables users to specify requirements and enables analysts to elicit and evaluate requirements, both of which are necessary elements of RD. Urquhart (1997) described such communication as complex, "concerned with how people assign meaning to what they hear and see and also how they make sense of the information they receive" (Lee \& Liebenau, 1997). In short, there is ample evidence of both the complexity and significance of communication during RD.

As a consequence, extensive research has been conducted on RD to improve the effectiveness of communication between stakeholders (Coughlan et al., 2003) through applying new approaches and models, such as different modes of group communication (Ocker, Fjermestad, Hiltz, \& Johnson, 1998), or enhancing cognitive fit (Browne \& Ramesh, 2002) or technique and methodology fit (Zowghi \& Coulin, 2005). In much of this research, however, attention to analysts' communication skills, behaviors, and interactions with other stakeholders has been limited, while technical issues have received most attention. Among the latter, Chen et al. (2005), while exploring analysts' communication skills, found a gap between the importance of communication skills and the perception of the presence of those skills in IS professionals. Al-Rawas and Easterbrook (1996) concluded that "organisational and social issues have great influence on the effectiveness of communication" contributing to the success or failure of the requirements engineering process. Their study revealed that informal communication, such as via telephone conversations, is the least used method by stakeholder groups when compared to meetings and face-to-face discussions.

The RD phase is founded on communication activities that are by necessity embedded in social interactions between analysts and users (Urquhart, 1997). Several researchers have therefore approached the analysis of IS development as a social practice (Robey \& Newman, 1996). Some argue that the social aspects of RD are of such importance that they may overshadow the substantial technical complexities. The intricacies of the relationships between social interactions and analysts' communication competence are still not well understood empirically or theoretically. With all of this in mind, this research examines RD from the perspective of a social practice. A social perception theory offered by Baron and Byrne in 1991 suggests that people perceive information differently due to the fact that every individual develops their own schema for understanding the world, which is based on personal experience, educational level, and working environment. This individually evolving schema has a significant influence on how individuals and information from outside the schema are interpreted. Only in the case of similarities in schemas would two individuals inherently rank the importance of matters similarly. Empirical support for this theory can be found in the IS literature in connection with IS users and staff and variations in experience and problem-solving skills (Jiang, Sobol, \& Klein, 2000).

Social perception theory and its empirical support exemplifies that there are many issues at play during 
interactions between analysts and users. One of these issues is variability in the social interaction skills that analysts employ to communicate with users. Our intent is to explore this issue, and here we report findings that address the following research questions: "What communication channels do novice analysts prefer?" and "How socially competent do novice analysts perceive themselves to be?" In order to answer these questions we have used a survey method to assess the communicative competence and capabilities of novice analysts in the form of final year capstone computing students. It could be expected that recently educated analysts would be acutely aware of the importance of social interaction in $\mathrm{RD}$ and so would exhibit appropriate characteristics in this regard. On the other hand, their lack of experience may make them anxious regarding communication with seasoned professional clients or users.

\section{Research Design}

Quantitative data were gathered by means of a survey questionnaire that included the Communicative Adaptability Scale (CAS) (Duran, 1992). In order to measure social communication competence, analysts' self-evaluation on six dimensions was conducted (see the Instrumentation section that follows). Self-evaluation assessments vary across constituent groups to accommodate the different interests and experiences of individuals (Ross, 2006). Self-report instruments are appropriate in cases when perceptions of one's own competence influence the way he or she communicates (Spitzberg, Greene, \& Burleson, 2003). Furthermore, Rubin (1985) stated that people might have more knowledge about themselves across contexts than anyone else does, lending some support to the use of such a method.

\subsection{Sample}

Final year undergraduate software development students at Auckland University of Technology were selected for the study, to identify their perceived competencies in social interaction. While communicating with stakeholders (e.g. sponsors, customers, domain specialists), analysts are characterized by boundary-spanning behaviors - a type of behavior often evident during the act of connecting with external members. Ansett (2005) notes that the key skills associated with successful boundary spanners include empathy, open-mindedness, active listening, strong communication skills, and strong abilities to synthesize information, emotional maturity and integrity. In the context of this study, a boundary-spanning behavior is broadly defined as the effective and appropriate management of social interactions (Kirsch, Sambamurthy, Ko, \& Purvis, 2002). The six dimensions of social interactions captured by the CAS (social experience, social confirmation, social composure, appropriate disclosure, articulation, and wit) are appropriate for two reasons. First, contemporary understanding regarding $\mathrm{RD}$ is that external-to-the-team activities, such as keeping users involved and managing stakeholder expectations, will lead to better RD and higher levels of user satisfaction. Second, evidence from the RD literature indicates that teams who better manage their external dependencies perform better than those who only manage their internal dynamics.

The total number of final-year students developing software based on client needs in Auckland University of Technology's capstone course sits at just over 100. The questionnaire was sent by email to all students and they were allowed a period of time to reply to the questions or seek clarification. A hard copy was also made available to the students, to encourage completion. A total of 45 useable responses representing a $43 \%$ response rate was achieved. This is adequate, considering that the average survey response rate for students has been noted in the past to be approximately 57\% (Sekaran, 2006). Furthermore, Sekaran (2006) notes that "study of a sample rather than the entire population is also sometimes likely to produce more reliable results. This is mostly because fatigue is reduced and fewer errors will therefore result in collecting data". The sample mirrored the university's population distribution of $52 \%$ male and $48 \%$ female students. All respondents were between 20 and 29 years of age and were studying at a senior undergraduate level. All respondents had also taken a project and research paper in which they were required to develop a software system based on client needs.

\subsection{Instrumentation}

The Instrumentation contains two parts, each in the form of a questionnaire:

- Communication channels: questions targeting the perceptions of analysts regarding the most effective channels through which to receive and send information in order to indentify system requirements based on client/user needs.

- Communicative Adaptability Scale (CAS): The Communicative Adaptability Scale, first developed by Duran in 1983 and later refined (Duran, 1992), is a 30-item dispositional measure of social communicative competence. Duran (1992) described communicative adaptability as "the ability to perceive socio-interpersonal relationships and adapt one's interaction goals and behaviors accordingly". Communicative adaptability is 
proposed as a component of social communication competence. A comprehensive critical review of this instrument can be found in Spitzberg and Cupach (1989). These authors point out that the Communicative Adaptability Scale is one of the few reliable and valid measures of communication competence. Items are scored on a five-point Likert-type scale ranging from (5) always true to (1) never true. Duran (1992) reports reliabilities ranging from 0.74 to 0.84 . Although developed as a self-reported measure of communication competence, it has been used to report on the competence of "others". As such it is a previously developed and validated multi-dimensional instrument addressing the following six dimensions:

- Social experience, which measures a person's ability and desire to communicate in a novel social context. Individual experience of social communication over time leads to refinement of a person's abilities to interact in different contexts.

- Social composure, which measures the psychological reaction of a person in a social environment. Social composure reflects individual confidence to approach new people and situations.

- Social confirmation, which is the acknowledgment of the other's line or projected self-image.

- Appropriate disclosure, which measures the rating of intimacy one should apply in a particular situation during the communication process.

- Articulation, which measures an individual's ability to clearly express his or her ideas, which in its turn is measured by the choice of syntactical and grammatical structures that will be appropriate in a particular context.

- Wit, which measures the use of humor to diffuse social tension to help an individual handling an awkward situation.

Recent literature related to communication skills emphasizes the importance of a person's ability to choose from among a range of skills that would be the most effective and appropriate in a particular situation (Spitzberg \& Cupach, 2012). Spitzberg (2003) states, "The factor-structure of the CAS has been generally supportive of the predicted structure, but the precise item content of the subscales has varied considerably across studies. Despite these reservations, the CAS has generally revealed supportive relationships with other trait measures of competence and related constructs. It offers the advantage of a subscale structure which permits the examination of several distinct interpersonal skill constructs commonly associated with competent interaction". Thus CAS is a suitable instrument to use in this case as it enables analysts to reflect on RD method choice and it also brings predictability of that choice as well as structure and acceptable psychometrics (Spitzberg et al., 2003).

\subsection{Data Analysis}

Preliminary analyses were conducted in the first instance in order to ensure no violation of the underlying assumptions of normality required for our preferred statistical tests. Deviations from normality were diagnosed using residual plots and assessments of skewness and kurtosis, as well as normal probability plots (on which the points will lie in a reasonably straight diagonal line from bottom left to top right if there are no major deviations from normality) (Spitzberg et al., 2003). In order to summarize and present the collected data in an accessible format descriptive statistics have been used, drawn from analysis conducted using the Statistical Package for Social Science (SPSS), version 19.0.

Questions regarding analysts' preferred communication channels considered seven such channels for receiving and sending information relating to client/user needs. A five-point Likert-type scale rating from 1= "very little" to $5=$ "very much" was used to rate each respondent's preference for the communication channels. Table 1 presents the details of the communication channels questionnaire.

Table 2 shows the questionnaire items used to measure two of the six CAS dimensions as examples (due to space limitations), and indicates which of them needs to be reversed in scoring during the analysis as indicated by "(R)". For each of these items the scores were changed in the following way: if the score is a 5 , change it to a 1 and vice versa; a score of 4 should be changed to a score of 2 and vice versa; and a score of 3 stays as is. A five-point Likert-type scale rating from $1=$ "never true of me" to $5=$ "always true of me" was used for all six CAS dimensions.

\section{Findings and Results}

\subsection{Communication Channels}

Tables 3 and 4 depict the results of the communication channel preference analysis in respect to RD information transmitted to users and received from them. It can be seen that Face-to-Face channels are the most preferred, followed by two other traditional communication channels: Written and Telephone. These results lend support to previous observations about communication channels used and/or preferred during $\mathrm{RD}$ and indicate that novice 
analysts' preferences are in line with those of other more experienced professionals.

\subsection{Perceived Communicative Competence}

Table 5 portrays the results of analysts' self-reported communication adaptability scale scores. Higher average ratings were received for social experience (median $=4.0$, mean $=3.8$ ) and social confirmation (median $=3.8$, mean $=3.7$ ); appropriate disclosure, articulation, and social composure received slightly lower average ratings (means ranging from 3.3 to 3.5); and wit received the lowest average self-rating (median $=2.8$, mean $=2.9$ ).

The next step in our analysis was an examination of any associations between the two sets of outcomes just described. This addressed the question considering whether social communication competence might be related to preference for specific communication channels. We conducted bivariate correlation analyses looking at relationships between the responses across our sample of novice analysts, and report the highly significant results (at $\alpha=0.01,2$-tailed) in Table 6 . Note that, due to the presence of a small degree of skewing, we show both Pearson's rho and Kendall's tau-b coefficients. The former assumes bivariate normal distributions but is a more powerful test for linear association; the latter makes no assumptions but is generally more conservative.

Table 1. Preferred Communication Channel Questionnaire

\begin{tabular}{|c|c|c|c|c|c|c|c|c|c|c|}
\hline \multirow{2}{*}{$\begin{array}{l}\text { Communication Channels } \\
\text { Face-to-Face Contact Between Two People }\end{array}$} & \multicolumn{5}{|c|}{$\begin{array}{l}\text { Prefer to Receive } \\
\text { Information }\end{array}$} & \multicolumn{5}{|c|}{ Prefer to Send Information } \\
\hline & 1 & 2 & 3 & 4 & 5 & 1 & 2 & 3 & 4 & 5 \\
\hline $\begin{array}{l}\text { Face-to-Face Contact Among More Than } \\
\text { Two People }\end{array}$ & 1 & 2 & 3 & 4 & 5 & 1 & 2 & 3 & 4 & 5 \\
\hline Telephone & 1 & 2 & 3 & 4 & 5 & 1 & 2 & 3 & 4 & 5 \\
\hline Written & 1 & 2 & 3 & 4 & 5 & 1 & 2 & 3 & 4 & 5 \\
\hline Bulletin Boards & 1 & 2 & 3 & 4 & 5 & 1 & 2 & 3 & 4 & 5 \\
\hline Internal Publications & 1 & 2 & 3 & 4 & 5 & 1 & 2 & 3 & 4 & 5 \\
\hline $\begin{array}{l}\text { Internal Audio-Visual Media (Videotape, } \\
\text { Films, Slides) }\end{array}$ & 1 & 2 & 3 & 4 & 5 & 1 & 2 & 3 & 4 & 5 \\
\hline
\end{tabular}

Table 2. CAS Item Scoring Excerpt

\begin{tabular}{ll}
\hline Social Experience & \\
\hline Item\# & Item Score \\
1. I like to be active in different social groups. & 12345 \\
6. I find it easy to get along with new people. & 12345 \\
20. I enjoy socializing with various groups of people. & 12345 \\
24. I enjoy meeting new people. & 12345 \\
25. I do not "mix" well at social functions. (R) & 12345 \\
Appropriate Disclosure & \\
Item\# & Item Score \\
9. I am aware of how intimate my disclosures are. & 12345 \\
11. I know how appropriate my self-disclosures are. & 12345 \\
17. I disclose at the same level that others disclose to me. & 12345 \\
19. When I self-disclose, I know what I am revealing & 12345 \\
22. I am aware of how intimate the disclosures of others are. & 12345 \\
\hline
\end{tabular}


Table 3. Communication Channel Preference Ratings

\begin{tabular}{lll}
\hline Communication Channels & $\begin{array}{l}\text { Prefer To Receive } \\
\text { Information } \\
\text { Mean (SD) }\end{array}$ & $\begin{array}{l}\text { Prefer To Send } \\
\text { Information } \\
\text { Mean (SD) }\end{array}$ \\
\hline $\begin{array}{l}\text { Face-to-Face Contact Between Two } \\
\text { People }\end{array}$ & $4.3(0.94)$ & $4.2(1.06)$ \\
$\begin{array}{l}\text { Face-to-Face Contact Among More } \\
\text { Than Two People }\end{array}$ & $4.3(0.79)$ & $4.1(0.92)$ \\
Telephone & $2.9(0.96)$ & $3.1(1.12)$ \\
Written & $3.3(1.17)$ & $3.3(1.27)$ \\
$\begin{array}{l}\text { Bulletin Boards } \\
\text { Internal Publications }\end{array}$ & $2.7(0.92)$ & $2.8(1.12)$ \\
$\begin{array}{l}\text { Internal Audio-Visual Media } \\
\text { (Videotape, Films, Slides) }\end{array}$ & $2.9(1.06)$ & $2.5(1.00)$ \\
\hline
\end{tabular}

Table 4. Communication Channels - Detailed Analysis for Face-to-Face Channels

\begin{tabular}{lll}
\hline Face-to-face contact between two people & Receive & Send \\
\hline Mean & 4.3 & 4.2 \\
Median & 5.0 & 5.0 \\
Std. Deviation & 0.94 & 1.06 \\
Minimum & 1.0 & 1.0 \\
Maximum & 5.0 & 5.0 \\
Skewness & -1.64 & -1.27 \\
Kurtosis & 2.88 & 0.90 \\
Face-to-face contact among more than two people & Receive & Send \\
Mean & 4.3 & 4.1 \\
Median & 4.0 & 4.0 \\
Std. Deviation & 0.79 & 0.92 \\
Minimum & 3.0 & 1.0 \\
Maximum & 5.0 & 5.0 \\
Skewness & -0.57 & -1.01 \\
Kurtosis & -1.14 & 1.29 \\
\hline
\end{tabular}

Table 5. Communicative Competence Average Scores

\begin{tabular}{llll}
\hline Statistic & Social Experience & Social Composure & Social Confirmation \\
\hline Mean & 3.8 & 3.3 & 3.7 \\
Median & 4.0 & 3.2 & 3.8 \\
Std. Deviation & 0.76 & 0.53 & 0.60 \\
Minimum & 2.20 & 2.40 & 2.40 \\
Maximum & 5.00 & 4.20 & 4.80 \\
Skewness & -0.37 & 0.12 & -0.45 \\
Kurtosis & -1.15 & -0.81 & -0.15 \\
Statistic & Appropriate Disclosure & Articulation & Wit \\
Mean & 3.5 & 3.3 & 2.9 \\
Median & 3.4 & 3.2 & 2.8 \\
Std. Deviation & 0.63 & 0.87 & 0.78 \\
\hline
\end{tabular}




\begin{tabular}{llll}
\hline Minimum & 2.40 & 1.40 & 1.40 \\
Maximum & 5.00 & 5.00 & 4.80 \\
Skewness & 0.44 & -0.17 & 0.38 \\
Kurtosis & -0.49 & 0.10 & -0.28 \\
\hline
\end{tabular}

Table 6. Bivariate Correlation Analyses

\begin{tabular}{ll}
\hline Bivariate association & Statistics \\
\hline Receive via... & \\
Face-to-Face Contact Between Two People AND & rho: 0.48 \\
Social Experience & tau-b: 0.39 \\
Face-to-Face Contact Between Two People AND & rho: 0.40 \\
Social Composure & tau-b: 0.36 \\
Face-to-Face Contact Between Two People AND & rho: 0.48 \\
Social Confirmation & tau-b: 0.34 \\
Face-to-Face Contact Among More Than Two People AND & rho: 0.52 \\
Social Experience & tau-b: 0.44 \\
Face-to-Face Contact Among More Than Two People AND & rho: 0.41 \\
Social Composure & tau-b: 0.39 \\
Receive via Written AND & rho: -0.51 \\
Wit & tau-b: -0.37 \\
Send via... & \\
Face-to-Face Contact Between Two People AND & rho: 0.47 \\
Social Confirmation & tau-b: NS \\
Face-to-Face Contact Among More Than Two People AND & rho: 0.44 \\
Appropriate Disclosure & tau-b: 0.43 \\
Send via Written AND & rho: -0.45 \\
Wit & tau-b: -0.35 \\
Send via Internal Publications AND & rho: NS \\
Social Composure & tau-b: 0.34 \\
Send via Internal Audio-Visual Media AND & rho: 0.49 \\
Social Experience & tau-b: 0.39 \\
Send via Internal Audio-Visual Media AND & rho: 0.45 \\
Social Composure & tau-b: 0.36 \\
\hline
\end{tabular}

\section{Discussion}

The results indicate that different communication channel strategies are preferred for different purposes during RD. For instance, face-to-face interactions and those supported by internal publications (e.g. models) and A/V (e.g. shared screen, video conference) were preferred by analysts receiving information. In contrast, the use of phone calls and bulletin boards (e.g. wikis) was preferred by the novice analysts when they wished to send information to the clients. Written communication was seen as useful in both conveying and receiving information.

The results imply that novice analysts prefer to have direct interaction with the clients during the RD process. In other words, direct interactions with clients via synchronous channels - face to face, phone or video conference discussion or perhaps written email/chat - seem to be preferred in order to identify initial needs, to clarify their understanding of requirements, to identify possible improvements, and to understand the current business process. They may also prefer such direct interactions in order to build a relationship with the client. It is also evident that novice analysts prefer to use a face-to-face channel (Between Two People, Among More Than Two People) via client interviews and focus groups, in order to collect and confirm software requirements. The results suggest that the face-to-face channel is an important channel from novice analysts' perspective as perhaps one that could have an impact on the progress and outcomes of the requirements determination process.

Evidence gathered elsewhere suggests that this might be due to the fact that use of a face to face channel allows the analyst(s) to employ different (visual and other) tools during meetings, to send clear information and receive it from the users under a process of negotiation. Those tools may include a whiteboard, blank paper, prototype screens, through to body language. As concluded by Kirsch and Haney (2006) in their case study research, 
knowledge and use of such tools can help analysts to categorize the potential requirements and come to an agreement about requirements through negotiation and compromise with the user stakeholders. In identifying such requirements, both knowledge acquisition and negotiation skills are significant.

In addition, the results show that the written communication channel received slightly higher than average ratings for both the sending and receiving of information. These results imply that our novice analysts prefer to use written material as a secondary channel in order to collect and verify software requirements. Kirsch and Haney (2006) noted that the requirements determination process included a stage of knowledge acquisition, in which the participants sought to identify, document, and understand existing business processes and technologies. Project participants went about this task to elicit domain knowledge and catalogue potential requirements. Thus documents form a central means of recording and conveying requirements, an approach that appears to be valued by our novice analysts.

In looking at the novice analysts' communication competence in social interactions (using self-reported measures) the results show that, for our sample, social experience gets the highest mean and median ratings among the six CAS dimensions, suggesting that analysts perceive themselves to have the ability and desire to communicate in novel social contexts. The outcome of these experiences is the development and refinement of a social communication repertoire. Such a repertoire enables an individual to interact in various social contexts with different individuals. These capabilities are necessary to provide an individual with the confidence to approach a novel social setting. It appears that our analysts consider themselves to have the ability to interact in different contexts during communication processes.

One possible explanation for the novice analysts' belief in their social experience competence is that final project papers are selected from a variety of interesting areas such as hardware and computer architecture, operating systems and computer networks, or deal with social and legal issues. The variety of areas covered as well as the leading-edge nature of specific projects can encourage students to become well rounded in these areas, providing them with an opportunity to gain desired teamwork and interaction skills, since the projects include many stakeholders including team members, clients, a supervisor, and the course coordinators' panel. Furthermore, the final project paper incorporates a set of progress activities that require different oral presentation and interaction activities such as a proposal presentation, quality review presentations, client meetings, supervisor meetings, and team meetings. These activities may improve the analysts' social experience competence skills.

Moreover, the results show that the dimension of social confirmation received high average ratings. As stated above, one component of adaptability is the need to conform to the exigencies of the physical, social, and relational context. These results imply that our sample of novice analysts perceive themselves to have the ability to adapt to the relational context via their recognizing and confirming the results that their clients expect.

On the other hand, the results show that the dimensions of appropriate disclosure, composure, and articulation received slightly lower average ratings. These results imply that novice analysts perceive themselves to have a lesser degree of appropriate disclosure, a measure which assesses sensitivity in their understanding of social exchanges. Furthermore, novice analysts perceive themselves to have a lesser degree of competence in clearly expressing their ideas. In other words, the analysts may have lesser competence in terms of their word choice, pronunciation, and grammatical structure, or they may not express ideas in a manner appropriate to the social context.

Two possible explanations for these outcomes can be put forward. First, software development, software engineering, and requirements determination courses pay relatively less attention to the development of communication skills compared to the achievement of technical prowess. There is some evidence to indicate that, in university education, such oral communication techniques are often neglected (Teles \& de Oliveira, 2003). This is understandable in part, since the universities' lists of "need-to-know" topics continue to grow. We squeeze increasing numbers of knowledge units into our curricula to respond to the latest developments. However, it is not only technical knowledge that makes a good analyst or software engineer. Second, analysts may focus more on tangible achievements (deliverables) and goals rather than on applying management processes and communication strategies to deal with users. Without good communication skills, however, the analyst's abilities cannot be fully developed and the quality of those deliverables may suffer as a consequence.

The results also suggest that the novice analysts believe they have less ability to be calm, relaxed communicators who experience little communication anxiety in social situations. Duran, the developer of the CAS (Duran, 1992), linked lower levels of social composure with communication apprehension, shyness, and loneliness. The results for our sample show that social experience scored higher whereas the social composure, articulation and wit dimensions scored relatively lowly. On reflection, this is perhaps understandable. In talking with the novice 
analysts the opinion many had was that interactions with team members, supervisors and the course coordinators' panel were easier than interactions with the client, as they simply do not have sufficient experience to deal with genuine clients (this being their first time with a genuine client). Perhaps the novice analysts' anxiety will decrease over time, as they get to know the client better and build a relationship with them. Tan (1994) found that the relationship between rapport, summarizing other and acknowledgement is significant. Hence, having an ability to develop and maintain appropriate working relationships with various internal and external parties may have a significant effect on the efficacy of the RD process when conducted by a novice analyst.

Finally, the correlation analyses lead us to assert the following: there is a significant positive association between a preference for direct, synchronous interactions via face to face and video conference channels and the perceived communicative competence of our novice analysts. Note that we cannot at this point determine the direction of that association - whether preferred interactions lead to increased communicative competence, or vice versa. This is a matter for further empirical testing. Similarly, there is some evidence of a negative association between preference for written interchange and the handling of awkward situations via humor. This may reflect a sense that humor works most effectively in face to face settings.

6. Conclusions and Future Work

Analysts' skills and abilities to interact with users should be considered as key factors when seeking to improve the conduct and outcomes of the requirements determination process. Analysts can gain confidence, enhance their critical thinking capabilities and problem-solving skills, and improve their ability to communicate, interact, and co-operate during requirements determination, through improving their social interaction competence. Based on the responses of our 45 novice analysts, the face-to-face communication channel is the most preferred through which to receive and send requirements information. Given this, well-developed social interaction skills are needed to reduce misunderstandings and to increase the effectiveness of such communication. Moreover, the presence of analysts that have insufficient skills to work effectively during requirements determination, exhibiting flawed or poorly executed interaction skills, may also lead to dysfunctional teams and conflicts among team members, the result of which is an unsatisfactory experience for users and analysts alike. This study of social interaction competence should help to shed light on aspects of practice that an analyst can work on to minimize the likelihood of problematic requirements determination situations.

As this study is ongoing, future work will aim to develop a theoretical framework that explains the interaction strategies that analysts apply during the requirements determination process. This research will further consider the significance of interaction strategies and their impact on the effectiveness of requirements determination in the software development process.

\section{Acknowledgment}

The authors are grateful to the Applied Science Private University, Amman, Jordan, for the financial support granted to cover the publication fee of this research article.

\section{References}

Al-Rawas, A., \& Easterbrook, S. M. (1996). Communication problems in requirements engineering: a field study: National Aeronautics and Space Administration.

Ansett, S. (2005). Boundary spanner: The gatekeeper of innovation in partnerships. Paper presented at the Accountability Forum.

Baruch, Y. (1999). Response rate in academic studies-A comparative analysis. Human relations, 52(4), 421-438. http://dx.doi.org/10.1177/001872679905200401

Bostrom, R. P. (1989). Successful application of communication techniques to improve the systems development process. Information \& Management, 16(5), 279-295. http://dx.doi.org/10.1016/0378-7206(89)90005-0

Browne, G. J., \& Ramesh, V. (2002). Improving information requirements determination: a cognitive perspective. Information \& Management, 39(8), 625-645. http://dx.doi.org/10.1016/S0378-7206(02)00014-9

Chen, H. H., Miller, R., Jiang, J. J., \& Klein, G. (2005). Communication skills importance and proficiency: perception differences between IS staff and IS users. International Journal of Information Management, 25(3), 215-227. http://dx.doi.org/10.1016/j.ijinfomgt.2004.12.002

Coughlan, J., Lycett, M., \& Macredie, R. D. (2003). Communication issues in requirements elicitation: a content analysis of stakeholder experiences. Information and Software Technology, 45(8), 525-537. http://dx.doi.org/10.1016/S0950-5849(03)00032-6 
Duran, R. L. (1992). Communicative adaptability: A review of conceptualization and measurement. Communication Quarterly, 40(3), 253-268. http://dx.doi.org/10.1080/01463379209369840

Gallivan, M. J., \& Keil, M. (2003). The user-developer communication process: a critical case study. Information Systems Journal, 13(1), 37-68. http://dx.doi.org/10.1046/j.1365-2575.2003.00138.x

Havelka, D. (2002). Requirements determination: An information systems specialist perspective of process quality. Requirements Engineering, 6(4), 220-236. http://dx.doi.org/10.1007/PL00010361

Jiang, J. J., Sobol, M. G., \& Klein, G. (2000). Performance ratings and importance of performance measures for IS staff: the different perceptions of IS users and IS staff. Engineering Management, IEEE Transactions on, 47(4), 424-434. http://dx.doi.org/10.1109/17.895338

Kirsch, L. J., \& Haney, M. H. (2006). Requirements determination for common systems: turning a global vision into a local reality. The Journal of Strategic Information Systems, 15(2), 79-104. http://dx.doi.org/10.1016/j.jsis.2005.08.002

Kirsch, L. J., Sambamurthy, V., Ko, D. G., \& Purvis, R. L. (2002). Controlling information systems development projects: The view from the client. Management Science, 48(4), 484-498. http://dx.doi.org/10.1287/mnsc.48.4.484.204

Lee, A. S., \& Liebenau, J. (1997). Information systems and qualitative research: Springer. http://dx.doi.org/10.1007/978-0-387-35309-8

Ocker, R., Fjermestad, J., Hiltz, S. R., \& Johnson, K. (1998). Effects of four modes of group communication on the outcomes of software requirements determination. Journal of Management Information Systems, 99-118.

Pallant, J. (2007). SPSS survival manual: A step-by-step guide to data analysis using SPSS version 15. Maidenhead, Berkshire, England: McGraw-Hill Education.

Robey, D., \& Newman, M. (1996). Sequential patterns in information systems development: an application of a social process model. ACM Transactions on Information Systems (TOIS), 14(1), 30-63. http://dx.doi.org/10.1145/214174.214178

Ross, J. A. (2006). The reliability, validity, and utility of self-assessment.

Rubin, R. B. (1985). The validity of the communication competency assessment instrument. Communications Monographs, 52(2), 173-185. http://dx.doi.org/10.1080/03637758509376103

Sekaran, U. (2006). Research methods for business: A skill building approach: John Wiley \& Sons.

Siau, K., Tan, X., \& Sheng, H. (2010). Important characteristics of software development team members: an empirical investigation using Repertory Grid. Information Systems Journal, 20(6), 563-580. http://dx.doi.org/10.1111/j.1365-2575.2007.00254.x

Siminoff, L. A., \& Step, M. M. (2005). A communication model of shared decision making: accounting for cancer treatment decisions. Health Psychology, 24(4S), S99. http://dx.doi.org/10.1037/0278-6133.24.4.S99

Spitzberg, B. H., Greene, J., \& Burleson, B. (2003). Methods of interpersonal skill assessment. Handbook of communication and social interaction skills, 93-134.

SPITZBERG, B., \& Cupach, W. (2012). Handbook of interpersonal competence research: Springer Science \& Business Media.

Tan, M. (1994). Establishing mutual understanding in systems design: An empirical study. Journal of Management Information Systems, 159-182.

Teles, V. M., \& de Oliveira, C. E. T. (2003). Reviewing the curriculum of software engineering undergraduate courses to incorporate communication and interpersonal skills teaching. Paper presented at the Software Engineering Education and Training, 2003.(CSEE\&T 2003). Proceedings. 16th Conference on. http://dx.doi.org/10.1109/csee.2003.1191373

Urquhart, C. (1997). Exploring analyst-client communication: using grounded theory techniques to investigate interaction in informal requirements gathering Information systems and qualitative research (pp. 149-181): Springer.

Walz, D., \& Wynekoop, J. L. (1997). Identifying and cultivating exceptional software developers. Journal of Computer Information Systems, 37(4), 82-88. 
Yilmaztürk, N. (2005). "Good Quality" Requirements in Unified Process Engineering and Managing Software Requirements (pp. 373-403): Springer. http://dx.doi.org/10.1007/3-540-28244-0_17

Zowghi, D., \& Coulin, C. (2005). Requirements elicitation: A survey of techniques, approaches, and tools Engineering and managing software requirements (pp. 19-46): Springer.

\section{Copyrights}

Copyright for this article is retained by the author(s), with first publication rights granted to the journal.

This is an open-access article distributed under the terms and conditions of the Creative Commons Attribution license (http://creativecommons.org/licenses/by/3.0/). 